\title{
Bridging skills demand and supply in South Africa: The role of public and private intermediaries
}

Submitted to Development Southern Africa

\author{
Il-haam Petersen*
}

Post-Doctoral Research Fellow, Education and Skills Development, Human Sciences

Research Council, South Africa; e-mail: ipetersen@hsrc.ac.za

\section{Glenda Kruss}

Director, Education and Skills Development, Human Sciences Research Council, South Africa

\section{Simon McGrath}

Professor of International Education and Development, School of Education, University of Nottingham, United Kingdom, and Extraordinary Professor, University of the Western Cape, South Africa

\section{Michael Gastrow}

Senior Research Specialist, Education and Skills Development, Human Sciences Research Council, South Africa

*Corresponding author

\section{Acknowledgements}

The research was conducted under the Labour Market Intelligence Partnership, a research consortium led by the Human Sciences Research Council, South Africa, and funded by the Department of Higher Education and Training. We acknowledge a large team of researchers who participated in the data-gathering and analysis process, as well as all of those who participated in the case studies. 


\section{Bridging skills demand and supply in South Africa: The role of public and private intermediaries}

Demand-led skills development requires linkages and coordination between firms and education and training organisations, which are major challenges considering that each represents a "self-interested" entity. The need for a 'collaborative project' involving government, firms, universities and colleges, and other bodies is thus increasingly recognised. However, the crucial role of intermediaries has been largely overlooked. The paper addresses this gap by investigating the main roles of public and private intermediaries across three case studies: sugarcane growing and milling, automotive component manufacturing, and the Square Kilometre Array (SKA) sectoral systems of innovation. The research highlights the need for a move towards systemic thinking, to bridge across public and private objectives. It shows that private intermediaries play a larger role than is recognised in policy; that public-private intermediaries play crucial roles in coordination; and the potential for public intermediaries to contribute more effectively to systemic functioning.

Keywords: sectoral intermediaries; skills development; South Africa; sugarcane growing and milling; Square Kilometre Array (SKA); automotive components manufacturing 


\section{Introduction}

Skills mismatch is a major concern for economic and social development in South Africa. Following international examples, government is promoting a demand-led approach to skills development, to improve alignment between the qualifications and skills produced by education and training systems and labour market demand. Demandled skills development requires linkages and coordination between firms and education and training organisations, which are major challenges considering that each represents a "self-interested" entity.

To address these challenges, the role of intermediaries has been highlighted in the skills literature (Kraak et al, 2006; Kraak, 2008) and in policy (DHET, 2013a, 2013b). The focus has been on the role of public intermediaries such as the Sector Education and Training Authorities (SETAs) in facilitating bilateral relations, and linking the state and employers. However, as the innovation studies literature shows, other public intermediaries such as public research institutes, and private intermediaries such as industry associations and unions may also take on the role of intermediaries. They may facilitate linkages not only with the state, but between firms and (groups of) universities or colleges, to strengthen communication across the system and facilitate coordination to address systemic weaknesses (Howells, 2006; Intarakumnerd and Chaoroenporn, 2013a, 2013b; Klerkx and Leeuwis, 2008; van Lente et al, 2003).

This paper therefore argues for the need to better understand the roles of public and private intermediaries in skills development, to improve alignment between skills demand- and supply-side actors. Given the limited view of intermediaries in the skills 
literature, we draw on the innovation studies literature, where the notion of intermediaries is most well-developed, for insight into intermediary roles in skills development. Considering that sectoral contexts shape intermediary roles, we use a sectoral systems of innovation (SSI) approach (Malerba 2005: 64). Grounded in evolutionary economics, the SSI approach emphasises three components: common knowledge bases and similar technologies, actors and networks, and institutions (i.e. formal and informal rules for behaviour such as national policy and cultural values). With this emphasis, the approach offers a way to extend the political economy approach (Brown et al 2001) that dominates the skills literature.

Specifically, the paper addresses a key question: What are the roles of public and private intermediaries in facilitating alignment between skills demand-and supply-side actors, and how do the roles differ by sector? We identify the main intermediaries supporting skills development, and analyse and compare their roles across three SSIs, each currently prioritised by industrial development policy. The selection of cases enables comparison of current practice across an agro-processing, a medium-technology and a high-technology-(type) sector.

Section 2 returns to the literature to define the concept of "sectoral intermediaries" and discuss existing research on the roles of intermediaries in SSIs. A description of the methodology and cases are provided in Sections 3 and 4, which shows that whether public or private intermediaries take the lead is influenced by the type of actors and networks, technology and knowledge challenges, and institutional contexts of the SSI. Section 5 builds on this understanding by analysing the coordinating role of sectoral 
intermediaries in each case. The analysis shows how a focus on either public or private sector interests may create weaknesses in the skills development system. The final section thus argues for systemic thinking that promotes bridging across public and private objectives, and proposes that private sector actors should be included as potential partners in the 'collaborative project' (DHET, 2013a: 9) of skills development.

\section{The roles of public and private intermediaries in sectoral systems of innovation}

\subsection{What are public and private sectoral intermediaries?}

The notion of intermediaries is most well-developed in an emergent literature on innovation intermediaries. The literature has focussed on delineating what innovation intermediaries are and the range of functions or roles in enabling innovation (Dalziel, 2010; Dutrénit et al, 2012; Howells, 2006; Intarakumnerd and Chaoroenporn, 2013a, 2013b; van Lente et al, 2003). We define sectoral intermediaries as organisations in sectoral systems of innovation (SSI) that connect, translate and facilitate information flows (van Lente et al, 2003: 248) as well as offer services that are essential but not easily available in the system. An SSI refers to a set of actors organised around specific types of productive activities and technologies, within distinct geographical and institutional settings (Malerba, 2005). Sectors are thus referred to as dynamic systems shaped by interaction and the co-evolution of their components.

Sectoral intermediaries (hereinafter referred to as intermediaries) may engage in one-toone or one-to-many relations, not only to broker relations or mediate between actors, but also to promote learning and create dynamism. Services provided to support skills 
development and planning may include training, advisory services, quality control, funding, and so on. We thus follow Dalziel (2010) to focus on the organisational purpose of intermediaries rather than their activities.

Intarakumnerd and Chaoroenporn (2013a, 2013b) introduce a further distinction that is useful for our purposes: public intermediaries, which are publicly-funded organisations that focus on mainly public good objectives, especially those related to policy; and private intermediaries, which are privately funded and focus more on industry or firmspecific issues. The classification is useful because it considers the institutional structure and main objectives of an intermediary, which influence the organisation's form of management and performance assessment, and its functions (Intarakumnerd and Chaoroenporn, 2013a, 2013b; Klerkx and Leeuwis, 2008; Smits and Kuhlmann, 2004).

As Klerkx and Leeuwis (2008) indicate, organisations with a hybrid institutional structure, i.e. public-private, may also emerge as intermediaries. They show that these intermediaries typically engage in innovation management and liaison activities at the interface, and are responsible for interface management within innovation systems.

\subsection{Division of labour and coordination between public and private intermediaries in sectoral systems of innovation}

Considering that sectors differ in their knowledge bases, networks of actors, and policy or institutional contexts, sectoral differences matter for understanding innovation (Malerba 2005). Few studies have, however, explored sectoral differences in the roles of intermediaries. 
To address this gap, Intarakumnerd and Chaoroenporn (2013a, 2013b) compared the traditional roles of public and private intermediaries in different SSIs, drawing on a widely used set of distinctions:

- Consultant - providing information and advice in the recognition, acquisition and utilisation of relevant intellectual property or knowledge and technology capability.

- Broker - 'brokering a transaction between two or more parties'.

- Mediator - being an independent 'third party' who assists two organisations to form a mutually beneficial collaboration.

- Resource provider - being an agent who secures access to funding as well as other material support for the innovation outcomes of such collaborations (Howard Partners, 2007: 13).

According to Intarakumnerd and Chaoroenporn (2013a, 2013b), while mediumtechnology sectors tend to be strongly disciplined by transnational corporations (TNCs), agro-processing sectors generally consist of a small group of large firms and a large group of small (mainly local) firms. Intermediaries in agro-processing sectors are thus needed to broker relations among actors in the sector to assist in developing capabilities and ensure that their products and services meet sector-specific standards. Dutrénit et al (2012) and Klerkx and Leeuwis (2008) add that the articulation of demand is particularly important, as farmers often find it difficult to express their needs. In medium-technology sectors, on the other hand, intermediaries are needed to negotiate with TNCs to provide assistance to local firms to develop capabilities. Similarly, in high-technology sectors, an important task of intermediaries is to keep up with 
technological change, and broker relations between local actors and TNCs.

Government agencies and industry associations tend to play a key role as resourceproviders and brokers (in agro-processing sectors) or as mediators (in mediumtechnology sectors. In high-technology sectors, public research institutes and international industrial associations tend to emerge as the main intermediaries.

It is imperative for intermediaries to be knowledgeable about the actors and networks operating in the sector and the main challenges they face, in order to address systemic blockages, gaps and problems. However, since no single organisation can fill all of the gaps, a range of organisations may perform different intermediary roles within a system. It is thus crucial that the efforts of these organisations are coordinated to some extent as a lack of effective coordination may lead to tension and misalignment, which in turn, may weaken the system (Intarakumnerd and Chaoroenporn, 2013a, 2013b). For example, if a public intermediary does not have sufficient funds for its skills programmes, or if the division of labour between public and private intermediaries is not clear, the result may be competition with private intermediaries, weakening the SSI. A 'one-size-fits-all' approach to policy intervention or the crowding out of private intermediaries by government may thus have detrimental effects (Dutrénit et al, 2012; Intarakumnerd and Chaoroenporn, 2013a; Klerkx and Leeuwis, 2008).

This highlights the importance of systemic thinking, which is especially important in systems in transition, where change is rapid and dramatic (Smits and Kuhlmann, 2004; 
Van Lente et al, 2003). Smits and Kuhlmann (2004: 18) point out the need for policy instruments that promote systemic functioning, and refer to these as 'systemic instruments'. Systemic functions include: management of interfaces, which is not limited to bilateral relations; building and organising systems; creating conditions for learning and experimenting; providing an infrastructure for strategic intelligence; and stimulating demand articulation, strategy and vision development (Smits and Kulmann, 2004 in Van Lente et al, 2003: 254-255). While the focus in the literature has been on the traditional roles of intermediaries (see Howells, 2006), van Lente et al (2003: 256) suggest the emergence of a new type, a 'systemic intermediary'. Typically, these aim to satisfy the need for the articulation of options and demand, and the alignment of actors and possibilities, and support for learning processes by enhancing feedback mechanisms and stimulating learning.

Here, we explore sectoral differences in the roles of public and private intermediaries in supporting skills development, using the commonly used traditional roles as a starting point. We then go on to investigate the extent to which key intermediaries carry out systemic functions to facilitate alignment between skills supply- and demand-side actors.

\section{Methodology}

\subsection{Case study methodology of the larger project}

The research is part of a larger research project that draws on a case study methodology to explore alignment between skills supply and demand in South Africa (see Kruss \& Petersen, 2014, for a full description of the design and methodology). We focused on sugarcane growing and milling in KwaZulu-Natal, the region accounting for $85 \%$ of the 
sugar produced nationally (NAMC, 2013); "tier 1 firms", that is, the main component suppliers to the global automotive manufacturers, in the Eastern Cape; and the SKA project, with a national scope. The SKA is a big science project rather than an industrial 'sector', but as a clearly defined operational area, including both science and engineering aspects, it is in line with Malerba's (2005) definition of a SSI.

With a focus on the skills development networks for each SSI, we constructed maps of the key role-players involved as demand-side actors (all types of employers of all sizes), supply-side actors (public and private education and training organisations) and sectoral intermediaries (including government departments and agencies, industry associations, employee associations or research institutes). The selection of education and training organisations was based on whether they offered programmes in fields of study important for meeting skills shortages and skills gaps in the sector. Government departments were included only if they were involved in sector-specific intermediary activities. For example, the Department of Higher Education and Training (DHET) conducts detailed quantitative skills planning for eighteen priority Strategic Integrated Projects (SIPs), including the SKA.

In total, 220 semi-structured interviews were conducted with representatives of these organisations: 67 for the sugar case, 81 for the automotive case and 72 for the SKA case. At the sectoral intermediaries, we interviewed managers to understand the ways in which their organisations support skills development within the SSI (6, 14 and 10 managers respectively). For this paper, we mined the data to investigate and compare 
the roles of private and public intermediaries across the three SSIs.

\subsection{Analysis in this paper}

The analysis was conducted in two steps. Drawing on the work of Intarakumnerd and Chaoroenporn (2013a, 2013b), we firstly categorised the intermediaries as public or private, distinguishing between the ultimate objectives of their activities as either for public good or private gain. Secondly, we compared the roles of each intermediary in facilitating alignment between skills demand- and supply-side actors. Intermediary roles were classified according to the four main roles of "traditional" intermediaries identified in the literature review above: resource-provider, consultant, broker and mediator. Thirdly, we selected one key role, the role of coordinator, for further analysis, to facilitate in-depth comparison across the cases.

\section{Case studies: The challenge of alignment in each sector}

\subsection{The challenge of alignment for meeting changing skills needs in the sugar sector}

The sugar sector is one of the oldest and most important agro-processing sectors in South Africa. The milling segment is concentrated in a small number of large companies while sugarcane production is dominated by small-scale growers (SASA, 2013). Growth in the sector has been hindered by difficulty in exporting profitably to the world market, given subsidy-induced overproduction in some major sugarproducing countries, tariff restrictions and preferential trade arrangements, added to the negative impact of cheap imports in the domestic market. Other major challenges include the need to harness opportunities to diversify, especially the growing potential for serving the need for renewable energy; loss of skills due to an ageing population and competition from other industries; and the overwhelming number of new entrants to 
sugarcane growing, particularly land reform farmers ${ }^{1}$ and co-operatives, requiring soft skills and business management skills. These challenges present the need for new models to meet changing skills needs.

Private intermediaries lead skills development and planning, especially with regard to the growers, as technological capabilities are generally low among the small-scale growers. The core private intermediaries include industry associations representing the sugarcane growers and millers, which together formed an umbrella industry association mandated to support and coordinate activities pertinent to the sector. These intermediaries are well-established and well-resourced, and date back to the mid-1900s. A collective culture among the growers and millers is essential considering their mutually dependent relationship. Within an enabling environment (with policy allowing the sector to operate independently), the industry associations have worked together with employers to develop a self-sufficient skills development system, with all sugarspecific education and training taking place "in-house" (Petersen, 2015).

The sugar sector also has world-renowned agricultural and industrial research platforms that perform intermediary roles supporting skills development in a complementary way. One is a division of the umbrella industry association, which mainly focuses on research and development and education and training for sugarcane growers, and the other is an independent research institute that serves the needs of milling companies. The self-

\footnotetext{
${ }^{1}$ These are beneficiaries of land reform projects implemented as part of the government's land restitution and redistribution policy.
} 
sufficient skills development system is supported by public intermediaries, particularly the Agricultural SETA (AgriSETA), to an extent.

\subsection{The challenge of coordinating new technological capabilities in the automotive sector}

The automotive sector is a major employer with a significant multiplier effect, and a vital part of South Africa's export strategy. It is strongly disciplined by global production chains. The Industrial Policy Action Plan III therefore identifies a pressing need to support the local component sector to strengthen its position globally through technological upgrading. Much of the upgrading to meet routine skills needs is conducted in-house, and what firms require from external providers are short courses. This is something public providers are generally poorly placed to deliver. Interaction between employers and public education and training providers is thus ad hoc.

The skills development network is dominated by public intermediaries: four government agencies (the Manufacturing, Engineering and Related Services SETAmerSETA, an industry development centre and two industrial development zone offices), and two regional consortia that provide platforms for interaction among firms, education and training organisations, and intermediaries in the province. These forums focus on provincial competitiveness and the majority are not sector-specific. The SETA is one of the largest in the country, with strong employer and union representation and considerable internal capacity.

Four national private intermediaries are active, including a union and industry 
associations, some of which have strong provincial structures. The main private intermediaries are two industry associations representing the component manufacturing firms, with one also representing the OEMs. The union has a strong tradition of working in the skills sector over the past 25 years, and has a membership of nearly 400000 . A smaller industry body is mandated to promote exports, and identify key automotive industry export capabilities that typically lead to the identification of training needs, particularly among small and medium component manufacturers.

The automotive SSI thus includes a complex network of relationships and activities, with significant additional resources for skills development, much of which is directed at short courses and internal skilling of existing staff. Most initiatives are wellestablished and well-funded, reflecting the priority placed on the sector by national and provincial government. Coordination is thus essential, as is the need to create dynamism in the system in order to promote technological upgrading for the development of improved processes.

\subsection{The challenge of coordination in a big science project}

Similar to high technology sectors, big science projects like the SKA are challenged to keep up with changing skills needs due to rapid technological change, while linking into global networks. Hence, the task of coordination between skills supply- and demandside actors poses a major challenge. The SKA case thus provides insights useful for both big science projects and high technology sectors. The SKA is, however, different from high technology sectors in organisational arrangement, as local and international science facilities and government are key actors rather than TNCs. 
In recent years, astronomy has emerged as a growing niche within South Africa's national innovation system. Only five years ago, the skills pool was much smaller than it is currently. Dedicated research into skills requirement projections, matched with a high level of funding from government actors channeled into the higher education system, have rapidly grown the competences available to employers, and greatly increased South Africa's capabilities and competitiveness in the international arena over the last decade. A major skills challenge is the development of skills at the intermediate level as the local technical and vocational education and training (TVET) college lacks the necessary capabilities (Gastrow, 2015).

The SKA project office in South Africa acts as the main intermediary responsible for coordination. Given that the SKA project is embedded in a set of global innovation networks, the project office is similar in nature to an international industrial association, identified as one of the main types in high-technology sectors (Intarakumnerd and Chaoroenporn 2013b). The SKA project office is distinct from the key intermediaries in the other two cases, in that it prioritises the needs of the sector as well as national development goals. To highlight the distinct nature of this intermediary, we categorised this coordinating body as a public-private intermediary (cf. Klerkx and Leeuwis, 2008), extending the two-fold classification.

In addition, there is a set of national and international public intermediaries: two national government departments, a national government funding agency, two science facilities and a consortium of stakeholders in radio astronomy in Europe and Africa. 
In sum, this section highlighted the challenge of coordination of skills development activities across the three SSIs. It is evident that the profile of intermediaries supporting skills development in the big science case is very different from that of the agroprocessing and medium-technology cases. The sugar and automotive cases differ with regard to which types of intermediaries took the lead: private intermediaries play a leading role in the sugar case, whereas a large group of public intermediaries are active in the automotive case. Based on our understanding of the role of intermediaries in different sectors, we would expect that the roles of the intermediaries would differ as well. In the next section, we explore exactly how intermediary roles differ. To facilitate in-depth comparison, we explore sectoral differences in one intermediary role, the role of coordinator, to draw out lessons for other sectors and areas for policy intervention.

\section{The role of sectoral intermediaries in the collaborative project of aligning skills demand and supply}

Table 1 summarises and compares the roles of the key intermediaries in the three SSIs. In addition to the new 'public-private' category, we identified a new role: 'coordinator'. Coordination is crucial for the systemic approach highlighted by Smits and Kuhlmann (2004) and Van Lente et al (2003), to improve coherence and alignment between education and work (DHET, 2013a, 2013b). Hence, in this section we focus on analysing this role, comparing between the SSIs. How do different types of intermediaries coordinate skills development activities in their sectors? 
The discussion focusses on the intermediaries identified as 'coordinators' : the South African Sugar Association (SASA), the SKA project office in South Africa, and the Automotive Industry Development Centre (AIDC). The SETAs provide a degree of coordination although coordination is not part of their formal mandate. They are wellconnected in skills development networks and possess in-depth knowledge on skills needs and education and training options. The analysis will suggest that these intermediaries could potentially play a larger role.

\subsection{Coordination role of the umbrella industry association in the sugar case}

Three distinct qualities of the sugar SSI shape the role of SASA in supporting skills development: a mutually dependent relationship between the sugar growers and millers, a policy context that enables self-regulation, and a self-sufficient skills development system. Furthermore, as a long-standing agricultural sector, small-scale farmers with relatively low levels of technological capabilities dominate, and technological change is not rapid.

As an umbrella industry association, SASA is responsible for coordinating all activities common to the partnership between the growers and millers, including skills development. Its role in coordination is facilitated by its governance structure, which includes the main representative bodies of the growers and millers. SASA is able to communicate with its members informally and through regular planning meetings and workshops to keep up-to-date with skills needs, and develop mechanisms and strategies, in consultation with industry, to ensure that these needs are met. The SASA Council is thus a crucial mechanism for facilitating interaction and creating conditions of trust among the growers and millers, to strengthen communication and bring about a 
collective culture across the value chain. SASA also acts a bridge between government and industry, ensuring that the sector complies with policy and lobbying government when the need arises. Through these mechanisms, SASA manages to identify and articulate skills and training needs effectively.

Typical of agro-processing sectors, SASA has built capabilities to provide sugarspecific education and training through its organisational divisions. A manager at SASA summed up this resource-provider role, which is not a function of the key intermediaries in the other two cases:

...we are a one-stop shop of training and development needs in respect of core industry or strategically important industry skills... (SASA, Manager 1)

SASA developed tailor-made programmes and teaching experience, so that agricultural colleges and universities wanting to introduce sugarcane growing and/or milling have approached them for assistance. It thus plays an important role in setting standards and quality control.

SASA has worked with other private intermediaries to ensure complementarity and coordination. For example, the Sugar Milling Research Institute (SMRI) offers training for engineers and engineers-in-training at the high-skills level. As a manager indicated, the SMRI serves 'the factory side', whereas SASRI (a SASA division) serves 'the agricultural side' (SMRI, Manager 1). 
SASA reports grower development as a key part of its mandate (SASA, 2013). Working with local 'firms' to build their technological capabilities and articulating their needs are important intermediary roles in agro-processing sectors (Dutrénit et al, 2012; Intarakumnerd and Chaoroenporn, 2013a, 2013b; Klerkx and Leeuwis, 2008). Through consultation with its stakeholders, in 2013, SASA developed a proposal for a 'Sugar Industry Development Pathway' for the growing group of new (land reform) growers and cooperatives. SASA has also effectively used public-private partnerships. For example, it initiated a partnership agreement with government to implement a new settlement model to improve the sustainability of new land reform farmers.

While SASA plays a key role in coordinating skills development activities provided by the private sectors actors, management does not consider linking employers with education and training organisations as part of their mandate, as this quote indicates:

...SASA is not responsible for managing the relationship between other employers in the industry and those third parties [i.e. education and training organisations]... (SASA, Manager 1)

Since SASA has opted to address agricultural and intermediate-level engineering skills needs through its divisions, there may not be a need for such interface management and coordination. Furthermore, SASA's skills development activities are well-coordinated with the other key intermediaries, some of which manage the interface between firms and public education and training organisations to address specific skills needs. 


\subsection{Coordination role of a policy implementation agency in the automotive}

case

The Automotive Industry Development Centre (AIDC) is the only one of the relatively large number of public intermediaries with a focus on the automotive sector specifically. Established in 2003, it is a subsidiary of a publicly-funded economic development agency. It is governed by a Board and is under 'rigid monitoring' (AIDC, Manager). On the AIDC website, the organisation is described as

a project management driven organisation with a strong focus on technical engineering excellence and delivery, by providing world-class, affordable services related to the following key development focus areas: supplier development, supply chain development, skills development and training, and (staff) wellness (http://www.aidcec.co.za/services.html).

The use of a project-based approach makes it different from other types of intermediaries. Coordination is not part of the AIDC's mandate, but it has developed strong relations and in-depth knowledge of skills needs and education and training options through its projects. A limitation of a project-based approach is the tendency to focus on bilateral relations rather than coordination across networks of actors. The AIDC does, however, regularly run workshops with firms to keep up-to-date with skills needs and challenges.

Skills development is one of its 'core' activities (AIDC, Manager). The AIDC has contributed significantly to regional skills development policy. However, it focuses on 
firms, and managing the interface between government and firms:

...we make sure that we stay abreast of everything that is required of government...industry wants one thing, government wants another and you've got to almost go as a mediator (AIDC, Manager)

Mediating between TNCs and local firms to negotiate and lobby for support to build local technological capabilities is an important way in which intermediaries can support skills development. The research shows that the AIDC has strong relations with the firms in the SSI:

Because we're permanently working with the components manufacturers, we engage with them on a constant and consistent basis... (AIDC, Manager)

Through project implementation, it has developed strong relations with the TNCs and managed to broker a number of partnerships, identifying skills and qualifications needed and aligning actors to address those needs. It has tried to work around funding constraints by negotiating funding from TNCs to support specific projects (AIDC, Manager).

The AIDC plays a major role in the skills development part of the national Automotive Cluster Initiative, where it meets regularly with key actors, such as TVET colleges, firms, government departments and other intermediaries. The Cluster brings together private and public sector actors to support logistical infrastructure, skills development and supplier development. 
Through such mechanisms, the AIDC has developed a reputation as a "go to" organisation for intelligence on skills needs and education and training options, and for support with skills development (see also McGrath, 2015). To complement its role in managing the interface between government and firms, the AIDC could play a larger role in interface management across public and private sector actors. This role is currently missing in the SSI (see McGrath, 2015).

\subsection{The key roles of the SETAs in the sugar and automotive cases}

Skills development policy, most recently, the White Paper on Post-School Education and Training (2013), has mandated Sector Education and Training Authorities (SETAs) as key intermediaries to support the 'collaborative project' required to address scarce and critical skills (DHET, 2013a: 9; DHET, 2013b).

The SETAs stood out as key "traditional intermediaries" in the automotive and sugar cases. The 1998 Skills Development Act emphasises the SETA roles of resource provider and consultant. The SETAs are expected to identify and articulate skills needs, introduce education and training programmes needed, provide quality control and accreditation services, and manage funds from the skills levy. They work closely with firms and public and private education and training to carry out these tasks.

The SETAs also emerged as important brokers. In both cases, the SETAs possessed the two competencies important for the role of broker: connections with the key actors, and in-depth knowledge (Intarakumnerd and Chaoroenporn, 2013a) of skills needs in the 
SSI and relevant education and training opportunities. The SETAs are involved in advisory boards at the universities and some of the firms' training academies and intermediaries' forums. The interviewees at the firms, the universities, TVET colleges and intermediaries reported close relations with the SETAs, as these quotes illustrate:

...AgriSETA would be our, kind of, key strategic partner (SASA, Manager

1)

...we work with them [AgriSETA] very closely...even our

FET ...everything is coming from AGRISETA (Agricultural College1O, Manager 2).

...all our programmes are accredited with the merSETA...we have a very developed apprenticeship programme (Tyre Manufacturing Company1G, HR Manager).

The SETAs run projects, often in collaboration with firms and other intermediaries, to address specific gaps and problems and facilitate partnerships. For example, in the automotive case, merSETA facilitated a collaborative arrangement between a local public TVET college and a private training provider to run an accredited trade test centre, to address the lack of accredited private education and training organisations in rural areas.

The SETA sub-units are their main mechanisms for facilitating interaction and managing relations between government and private sector actors. These sub-units, which meet on a regular basis, include representatives from firms, industry associations, private training centres run by private intermediaries, and unions. 
The SETAs' mandate potentially allows these actors an advantage to become effective coordinators: access to top-down and bottom-up labour market intelligence; and close relations with firms, education and training organisations and government. The SETAs have been effective in "traditional" intermediary roles promoted by government, but also "systemic" intermediary roles: identification and articulation of needs and options; aligning actors to address the needs; supporting learning processes (Van Lente et al, 2003); and interface management (Klerkx and Leeuwis, 2008).

\subsection{How do public-private sectoral intermediaries support coordination in a big science project?}

The SKA SSI can be described as a system in flux. In the initial stages of the SKA project, there was a need for articulating and forecasting skills demand, identifying actors able to meet that demand, facilitating linkages among them and coordinating their skills development activities.

As a coordinating body, the SKA project office has close relations with all of the key actors in the SSI. It works closely with government in making strategic decisions, which is crucial considering that policy support and government funding are major drivers and enablers of skills development activities in the SSI. It is represented on the steering committee of the National Astrophysics and Space Sciences Programme (NASSP), a nationally coordinated postgraduate programme that includes the public universities active in astronomy. The NASSP is an important forum for building alignment and informing curriculum development that meets future skills requirements. This 
collaborative arrangement has facilitated coordination of major astronomy programmes.

The Human Capital Development Programme (HCDP) is the main mechanism through which the SKA project office coordinates and supports the cultivation of appropriately skilled human capital required to use the SKA telescope being built, and to participate in its design and construction. Initiating the HCDP depended on the capability of the SKA project office to identify education and training organisations with capabilities to meet skills needs, encourage their participation in the HCDP, and support their efforts to respond. As a publicly-funded programme, the broader aim of the HCDP is to develop the "ecosystem" of skills required for radio astronomy in South Africa, contributing to national development goals. Decisions about funding allocations for skills development and research are the product of intensive and widespread interaction with external stakeholders, including universities, principal investigators on science projects, and intermediaries. The HCDP organises an annual conference to facilitate interaction and build a sense of community and critical mass.

Another important, but less formally structured mechanism, is the "Universities Working Group", which was initiated to facilitate coordination among the universities. It facilitated the development of informal, personal relationships and networks that have been critical for coordination and collaboration. Personal networks are often precursors to formal interaction, as efficient communication "short cuts" and as channels for the exchange of tacit knowledge. 
Public TVET colleges do not have the same historical links with astronomy as the universities do. The SKA project office thus had to develop effective connections with the colleges to address the need for intermediate skills. To do so, it linked with one of the SETAs working with the relevant colleges.

The strategic emphasis on networking, collaboration and coordination has been crucial for the success of the SKA project.

\section{Policy implications: coordination and systemic thinking are crucial for aligning skills supply and demand}

The research provides evidence of the critical roles of public and private intermediaries and public-private intermediaries in skills development, to facilitate alignment between skills demand- and supply-side actors. The extent to which either type of intermediary leads skills development differs by sector, influenced by its historical trajectory, institutional environment, the specific skills challenges, and the capabilities of firms and education and training organisations to respond to skills needs. Intermediaries require in-depth sector knowledge, an understanding of the capabilities of education and training organisations, and collaborative effort. The research shows how different types of intermediaries use different mechanisms and strategies, particularly to address changing skills needs. Here, we draw out key lessons for other sectors and implications for policy.

\subsection{The unrecognised role of private sectoral intermediaries}

In keeping with their mandate, private intermediaries are more concerned to facilitate interaction among employers, and between employers and government bodies, than 
between employers and education and training organisations. They facilitate trust and a collective culture among private sector actors. Their importance in addressing misalignment in skills demand and supply at the sectoral level has not been recognised sufficiently in the South African context. They have the necessary expertise and social capital to provide and support sector-specific education and training, and to enlist support from public intermediaries, especially the SETAs, as needed.

One way to strengthen skills development systems is thus to increase funding support to private intermediaries who act on behalf of the sector, and not only in the narrow interests of an individual firm. Another way is to promote public-private partnerships where private intermediaries take the lead. Since private intermediaries focus on private interests, they are not, however, well-suited to coordinate across public and private interests (Van Lente et al, 2003).

\subsection{Public sector intermediaries' are well-suited to play a larger role in coordination}

Public intermediaries stand out as crucial to address skills mismatches and promote alignment within and across networks. Current policy emphasis has been on bilateral relations, in terms of linking government and employers, and employers and education and training organisations. However, there is a need to bridge across employer networks, government bodies, and education and training organisations, especially public education and training. SETAs are currently challenged to develop their capacity to function as brokers between industry, government and public education and training organisations, and as strategic partners for TVET colleges. Their capabilities to perform these roles could be improved, which is acknowledged in the White Paper for the Post- 
School Sector (2013). In the short-term, one way in which SETAs could bridge supplyand demand-side actors is by including representatives from public education and training organisations in their sub-sector committees.

\subsection{Public-private intermediaries play a coordinating role}

Public-private intermediaries are well-suited to take on the role of coordinating skills development activities across public and private domains, particularly for implementing big science projects and in sectors where change is rapid (cf. Van Lente et al, 2003). In such contexts, a systemic approach to skills development is needed to coordinate skills development locally, to facilitate interaction, and manage relations between the diverse set of local stakeholders with each other and into global innovation networks. Policy instruments that promote systemic functioning are thus crucial.

\section{Conclusion}

Sectoral intermediaries play a crucial role in improving alignment between skills demand and supply. The research shows that a move towards systemic thinking that promotes bridging across public and private objectives is required. Analysis of the case studies contribute an understanding of how different types of intermediaries support systemic functioning. We show how public intermediaries and public-private intermediaries are better suited to support systemic functioning (cf. Klerkx and Leeuwis, 2008; van Lente et al, 2003), and we identify specific mechanisms and strategies that can be used to facilitate coordination. In conclusion, we propose that new systemic policy instruments are required to facilitate these potentially valuable roles of aligning skills in the interests of national development. 


\section{References}

Brown, P, Green, A, \& Lauder, H, 2001. High skills globalization, competitiveness, and skill formation. Oxford University Press, Oxford.

Dalziel, M, 2010. Why do innovation intermediaries exist? Paper presented at the DRUID Summer Conference, 16-18 June, Imperial College London Business School, United Kingdom.

DHET (Department of Higher Education and Training), 2013a. Guidelines on the implementation of SETA grant regulations. DHET, South Africa.

DHET (Department of Higher Education and Training), 2013b. Ministerial task team on SETA performance. Report for the Minister of Higher Education and Training, Hon B Nzimande (MP). Government Gazette No 36747, August 16.

Dutrénit, G, Rocha-Lackiz, A, \& Vera-Cruz, AO, 2012. Functions of the intermediary organizations for agricultural innovation in Mexico: The Chiapas Produce Foundation. Review of Policy Research 29(6), 693 - 712.

Gastrow, M, 2015. Understanding interactive capabilities for skills development in sectoral systems of innovation: A case study of astronomy and the Square Kilometre Array telescope. LMIP Report 6. www.lmip.org.za Accessed 30 April 2015.

Howard Partners, 2007. The role of intermediaries in support of innovation. Report prepared for Department of Industry, Tourism and Resources, Australia. http://www.howardpartners.com.au/assets/innovation-intermediariespublication-report-apr-2007---final.pdf Accessed 27 August 2014.

Howells, J, 2006. Intermediation and the role of intermediaries in innovation. Research Policy 35, 715-728.

Intarakumnerd, P, \& Chaoroenporn, P, 2013a. The roles of intermediaries in sectoral innovation system in developing countries: Public organizations versus private organizations. Asian Journal of Technology Innovation 21(1), 108 - 119.

Intarakumnerd, P, \& Chaoroenporn, P, 2013b. The roles of intermediaries and the development of their capabilities in sectoral innovation systems: A case study of Thailand. Asian Journal of Technology Innovation 21(2), 99 - 114.

Klerkx, L, \& Leeuwis, C, 2008. Matching demand and supply in the agricultural knowledge infrastructure: Experiences with innovation intermediaries. Food Policy, 33(3), $260-276$. 
Kraak, A, 2008. Incoherence in the South African labour market for intermediate skills. Journal of Education and Work 21(3): 197 - 215.

Kraak, A, Lauder, H, Brown, P, \& Ashton, D, 2006. Debating high skills and joined-up policy. HSRC Press, South Africa.

Kruss, G, \& Petersen, I, 2014. Understanding interactive capabilities for skills development in sectoral systems of innovation: A tentative framework. LMIP Working Paper 2. www.lmip.org.za Accessed 23 April 2015.

Malerba, F, 2005. Sectoral systems of innovation: a framework for linking innovation to the knowledge base, structure and dynamics of sectors. Economics of Innovation and New Technology 14(1-2), $63-82$.

McGrath, S, 2015. Understanding interactive capabilities for skills development in sectoral systems of innovation: A case study of the Tier 1 automotive component sector in the Eastern Cape. LMIP Report 7. www.lmip.org.za Accessed 30 April 2015.

NAMC (The National Agricultural Marketing Council), 2013. Document 1: Overview of the sugar industry in South Africa: Contribution to social and economic development and contentious issues. In growing the sugar industry in South Africa. NAMC, Pretoria.

Petersen, I 2015. Understanding interactive capabilities for skills development in sectoral systems of innovation: A case study of the sugarcane growing and milling sector in KwaZulu-Natal. LMIP Report 8. www.lmip.org.za Accessed 30 April 2015.

SASA (The South African Sugar Association), 2013. The South African sugar industry directory 2012 / 2013. The South African Sugar Association, Mt. Edgecombe.

Smits, R, \& Kuhlmann, S, 2004. The rise of systemic instruments in innovation policy. International Journal of Foresight and Innovation Policy, 1(1/2), 4 - 32.

Van Lente, H, Hekkert, M, Smits, R, \& van Waveren, B, 2003. Roles of intermediaries in transition processes. International Journal of Innovation Management 7(3), 247-279. 
Table 1 Roles of sectoral intermediary organisations

\begin{tabular}{|c|c|c|c|c|c|c|}
\hline \multirow[b]{2}{*}{ Roles } & \multicolumn{2}{|c|}{$\begin{array}{l}\text { Square Kilometer Array (SKA) } \\
\text { project }\end{array}$} & \multicolumn{2}{|c|}{$\begin{array}{l}\text { Sugarcane growing and } \\
\text { milling SSI }\end{array}$} & \multicolumn{2}{|c|}{$\begin{array}{l}\text { Automotive component } \\
\text { manufacturers SSI }\end{array}$} \\
\hline & Public & Public-Private & Public & Private & Public & Private \\
\hline \multicolumn{7}{|l|}{ Resource provider } \\
\hline $\begin{array}{l}\text { Provision of funding and other } \\
\text { resources to private E\&T providers }\end{array}$ & & & $\begin{array}{l}\text { ETDP SETA; } \\
\text { AgriSETA }\end{array}$ & $\begin{array}{l}\text { SASMAL; } \\
\text { SASA }\end{array}$ & $\begin{array}{l}\text { merSETA; } \\
\text { AIDC }\end{array}$ & NUMSA \\
\hline $\begin{array}{l}\text { Provision of funding and other } \\
\text { resources to public E\&T providers }\end{array}$ & $\begin{array}{l}\text { DST; NRF; } \\
\text { AERAP }\end{array}$ & SKA & $\begin{array}{l}\text { AgriSETA; } \\
\text { DAFF; DoA, } \\
\text { KZN }\end{array}$ & SASMAL & $\begin{array}{l}\text { merSETA; } \\
\text { AIDC; CDC; } \\
\text { ECSECC }\end{array}$ & \\
\hline Setting standards for E\&T & DHET & & AgriSETA & & merSETA & \\
\hline
\end{tabular}




\begin{tabular}{|c|c|c|c|c|c|c|}
\hline Provision of E\&T & NRF (NASSP) & SKA & & $\begin{array}{l}\text { SASA - } \\
\text { SASRI, STC; } \\
\text { SMRI; } \\
\text { SACGA }\end{array}$ & & \\
\hline \multicolumn{7}{|l|}{ Broker } \\
\hline $\begin{array}{l}\text { Facilitating linkages between E\&T } \\
\text { organisations and employers }\end{array}$ & $\begin{array}{l}\text { AERAP; NRAO } \\
\text { (USA); NRF } \\
\text { (NASSP) }\end{array}$ & SKA & $\begin{array}{l}\text { AgriSETA; } \\
\text { DAFF; Dep. } \\
\text { Of Agriculture, } \\
\text { KZN }\end{array}$ & $\begin{array}{l}\text { SASA; } \\
\text { SASMAL; } \\
\text { SASTA; } \\
\text { SACGA }\end{array}$ & $\begin{array}{l}\text { merSETA; } \\
\text { CDC; PSDF; } \\
\text { ECSECC; } \\
\text { AIDC }\end{array}$ & NUMSA \\
\hline $\begin{array}{l}\text { Facilitating linkages between } \\
\text { employers and government bodies }\end{array}$ & $\begin{array}{l}\text { AERAP; NRAO } \\
\text { (USA) }\end{array}$ & SKA & AgriSETA & $\begin{array}{l}\text { SASA - } \\
\text { STC; } \\
\text { SACGA }\end{array}$ & $\begin{array}{l}\text { merSETA; } \\
\text { AIDC; CDC; } \\
\text { PSDF; } \\
\text { ECSECC }\end{array}$ & $\begin{array}{l}\text { NAAMSA; } \\
\text { AIEC }\end{array}$ \\
\hline
\end{tabular}




\begin{tabular}{|c|c|c|c|c|c|c|}
\hline $\begin{array}{l}\text { Facilitating linkages between } \\
\text { intermediaries }\end{array}$ & $\begin{array}{l}\text { AERAP; NRAO } \\
\text { (USA) }\end{array}$ & SKA & AgriSETA & SASA & $\begin{array}{l}\text { merSETA; } \\
\text { AIDC; CDC; } \\
\text { PSDF; } \\
\text { ECSECC }\end{array}$ & NAAMSA \\
\hline $\begin{array}{l}\text { Facilitating linkages between } \\
\text { employers }\end{array}$ & $\begin{array}{l}\text { AERAP; NRAO } \\
\text { (USA); SAAO }\end{array}$ & SKA & AgriSETA & $\begin{array}{l}\text { SASA; } \\
\text { SASMAL; } \\
\text { SMRI; } \\
\text { SACGA }\end{array}$ & $\begin{array}{l}\text { merSETA; } \\
\text { ELIDZ; } \\
\text { CDC; } \\
\text { ECSECC }\end{array}$ & $\begin{array}{l}\text { AIEC; } \\
\text { NAAMSA; } \\
\text { NUMSA; } \\
\text { NAACAM }\end{array}$ \\
\hline \multicolumn{7}{|l|}{ Consultant } \\
\hline Knowledge transfer and diffusion & $\begin{array}{l}\text { AERAP; NRAO } \\
\text { (USA); NRF } \\
\text { (NASSP) }\end{array}$ & SKA & $\begin{array}{l}\text { Dep. Of } \\
\text { Agriculture, } \\
\text { KZN }\end{array}$ & $\begin{array}{l}\text { SASA - } \\
\text { SASRI; } \\
\text { SACGA; } \\
\text { SMRI }\end{array}$ & AIDC & $\begin{array}{l}\text { AIEC; } \\
\text { NAAMSA; } \\
\text { NUMSA; } \\
\text { NAACAM }\end{array}$ \\
\hline
\end{tabular}




\begin{tabular}{|l|l|l|l|l|l|l|}
\hline Knowledge repository (on skills needs & AERAP; NRAO & SKA & AgriSETA & SASA - & merSETA & AIEC; \\
and skills supply pipeline) & (USA); NRF & & SASRI; & SACGA; & SMRI & NAMSA; \\
\hline Advise: development of skills needs \\
lists
\end{tabular}




\begin{tabular}{|c|c|c|c|c|c|c|}
\hline $\begin{array}{l}\text { Working with employers to identify } \\
\text { skills needs and communicate to } \\
\text { government bodies }\end{array}$ & NRF (NASSP) & SKA & AgriSETA & $\begin{array}{l}\text { SASA - } \\
\text { SASRI, STC; } \\
\text { SACGA; } \\
\text { SMRI }\end{array}$ & $\begin{array}{l}\text { merSETA; } \\
\text { CDC; AIDC }\end{array}$ & \\
\hline $\begin{array}{l}\text { Negotiating work placements for } \\
\text { students }\end{array}$ & NRF (NASSP) & SKA & AgriSETA & SASA - STC & $\begin{array}{l}\text { merSETA; } \\
\text { PSDF; } \\
\text { ECSECC; } \\
\text { ELIDZ }\end{array}$ & NUMSA \\
\hline $\begin{array}{l}\text { Negotiating between E\&T } \\
\text { organisations and government to } \\
\text { develop articulation between E\&T } \\
\text { organisations }\end{array}$ & NRF (NASSP) & SKA & $\begin{array}{l}\text { AgriSETA; } \\
\text { DAFF; Dep of } \\
\text { Agri, KZN }\end{array}$ & & & \\
\hline
\end{tabular}




\begin{tabular}{|c|c|c|c|c|c|}
\hline $\begin{array}{l}\text { Negotiate with government and/or } \\
\text { employers to support capabilities of } \\
\text { E\&T organisations }\end{array}$ & SKA & AgriSETA & $\begin{array}{l}\text { SASA; } \\
\text { SACGA; } \\
\text { SMRI }\end{array}$ & $\begin{array}{l}\text { merSETA; } \\
\text { AIDC; CDC; } \\
\text { PSDF; } \\
\text { ECSECC; } \\
\text { CDC; ELIDZ }\end{array}$ & \\
\hline $\begin{array}{l}\text { Negotiate with E\&T organisations } \\
\text { and/or government to tailor E\&T to } \\
\text { employers' needs }\end{array}$ & SKA & & $\begin{array}{l}\text { SASA; } \\
\text { SACGA; } \\
\text { SASMAL; } \\
\text { SMRI }\end{array}$ & AIDC & $\begin{array}{l}\text { NAACAM; } \\
\text { NAAMSA }\end{array}$ \\
\hline \multicolumn{6}{|l|}{ Coordinator } \\
\hline $\begin{array}{l}\text { Coordinate skills development activities } \\
\text { of private sector actors (firms, industry } \\
\text { associations, private research institutes) }\end{array}$ & SKA & & SASA & AIDC & \\
\hline
\end{tabular}




\begin{tabular}{|l|l|l|l|l|l|}
\hline $\begin{array}{l}\text { Coordinate programmes offered by } \\
\text { public and private E\&T providers }\end{array}$ & SKA & & & \\
\hline $\begin{array}{l}\text { Coordinate skills planning and skills } \\
\text { development across public and private }\end{array}$ & & SKA & & & \\
sector actors & & & & & \\
\hline
\end{tabular}

Source: Authors

Notes:

- Automotive sector intermediaries: AIDC=Automotive Industry Development Centre; AIEC=Automotive Industry Export Council; ECSECC=Eastern Cape Socio-Economic Consultative Council; PSDF=Eastern Cape Provincial Skills Development Forum; CDC=Coega

Development Corporation; ELIDZ=East London Industrial Development Zone; merSETA=Manufacturing, Engineering and Related Services Sector Education and Training Authority; NAAMSA=National Association of Automobile Manufactures of South Africa;

NAACAM=National Association of Automotive Component and Allied Manufactures; NUMSA= National Union of Metalworkers of South Africa 
- Sugar sector intermediaries: SACGA=South African Cane Growers' Association; SASA=South African Sugar Association; SASRI=South African Sugarcane Research Institute; STC=Shukela Training Centre; SASMAL=South African Millers' Association; SMRI= Sugar Milling Research Institute; AgriSETA=Agricultural Sector Education Training Authority; DAFF=Department of Agriculture, Forestry and Fisheries

- SKA intermediaries: AERAP=Africa Europe Astronomy Partnerships; DHET=Department of Higher Education and Training; DST=Department of Science and Technology; NRF=National Research Foundation; NASSP=National Astrophysics and Space Sciences Programme; NRAO=National Radio Astronomy Observatory (USA); SAAO=South African Astronomical Observatory; SKA=SKA project office 
